\title{
Colectivos de periodistas ante los cambios formativos y profesionales. Paralelismos con el discurso académico
}

\author{
Pilar SÁNCHEZ-GARCÍA \\ Universidad de Valladolid \\ pilar.sanchez@hmca.uva.es
}

Recibido: 18 de febrero de 2015

Aceptado: 10 de septiembre de 2015

\begin{abstract}
Resumen
El presente artículo analiza el paralelismo existente entre el discurso académico y el profesional en torno a tres temáticas interrelacionadas: las necesidades formativas de los periodistas, su adaptación a los cambios de perfiles multimedia y el reconocimiento de los titulados universitarios mediante una regulación profesional. El estudio recurre a una revisión documental y recaba la opinión de cinco colectivos profesionales mediante una entrevista con formulario abierto. Los resultados muestran una coincidencia en ambos discursos acerca de la necesidad de una sólida formación de los periodistas con planes de estudios que integren los nuevos perfiles. Al mismo tiempo, refleja la discrepancia de los colectivos periodísticos en torno a la regulación profesional basada en la titulación universitaria y cuya reivindicación no parece prioritaria en el ámbito académico.
\end{abstract}

Palabras clave: Periodismo, formación, perfiles, regulación profesional, estatuto.

\section{Journalistic organisations with regard to training and professional changes. Parallelisms with academic discourse}

\begin{abstract}
The present paper analyses the parallelism existing between academic and professional discourse regarding three interrelated subjects: journalists' training needs, their adaptation to multimedia profile changes and recognition of University graduates via professional regulation. This study relies on a bibliographical review and brings together the opinion of five professional groups by means of an interview using an open-ended questionnaire. The results show a coincidence in both discourses regarding the need for firmly grounded training of the journalists with study plans which integrate the new profiles. At the same time, it reflects the discrepancy of the journalistic groups with regard to professional regulation based on the University degree, whose vindication does not appear to be a priority in academic circles. Keywords: Journalism, programs, profiles, professional regulation, statute.
\end{abstract}

\section{Referencia normalizada}

SÁNCHEZ-GARCÍA, Pilar (2016): "Colectivos de periodistas ante los cambios formativos y profesionales. Paralelismos con el discurso académico". Estudios sobre el Mensaje Periodístico. Vol. 22, Núm. 1 (enero-junio), págs.: 531-547. Madrid, Ediciones Complutense.

Sumario: 1. Introducción; 1.1. Un debate abierto y en evolución. 2. Objetivos y metodología. 3. Resultados; 3.1. La revisión de las necesidades formativas y sus enfoques; 3.2. Los nuevos perfiles periodísticos como salidas laborales; 3.3. Discrepancias ante la regulación profesional y el estatuto fallido. 4. Discusión y conclusiones. 5. Referencias bibliográficas.

\section{Introducción}

La realidad cambiante de los medios de comunicación genera un profuso debate académico que encuentra su reflejo en el ámbito profesional. Desde un punto de vista científico existe un amplio y documentado interés en estudiar la transformación mediática en el marco de la Comunicación. En concreto, la nueva realidad periodística 
empuja a la búsqueda de nuevos modelos de negocio, soportes, estructuras, estilos narrativos, nuevos perfiles, usos de las audiencias, etc. Un interés que también existe en las redacciones, entre los colectivos de periodistas y en las propias empresas que analizan igualmente la realidad del sector, la situación laboral, las nueva rutinas productivas, las formas de regulación, o las vías cambiantes de financiación (APM, 2014; Jiménez, 2011), entre otras nuevas y viejas cuestiones. Existen, pues, dos discursos, el académico y el profesional con una reconocida necesidad de interrelación especialmente sobre la cuestión que puede considerarse que más les incumbe a ambos: la adaptación de las necesidades formativas, que ya demanda el mercado profesional, al nuevo entorno digital y multimedia formando profesionales capacitados técnicamente sin perder la multidisciplinariedad propia de la enseñanza superior (Pinto, 2003; López, 2009).

En este contexto, la presente investigación recaba la opinión de diferentes colectivos de periodistas y analiza los posibles nexos entre el discurso académico y el profesional en torno a tres temáticas concretas:

- Necesidades formativas de los periodistas

- Adaptación a los nuevos perfiles periodísticos

- Regulación profesional de periodistas titulados

Sobre estas cuestiones se establece una interrelación en el sentido de que las nuevas necesidades formativas de los periodistas pasan por una adaptación a los cambios de perfiles en la era digital (Mellado 2007; López, 2012; Palomo, 2013;), y por su posible reconocimiento, como titulados especializados, mediante una regulación profesional (Jiménez, 2011; Real, 2009). Una cuestión que se considera pertinente en el actual contexto de doble coyuntura de convergencia educativa europea y transformación de la Comunicación digital que provocan una reactivación del debate en torno a la formación más adecuada para trabajar en un sector en transformación.

\subsection{Un debate abierto y en evolución}

El viejo debate entre detractores y defensores de la enseñanza del Periodismo ha pasado por diferentes etapas, analizadas y recogidas a lo largo de varias décadas por investigadores que defienden la formación de los periodistas, como en los inicios de las primeras escuelas de periodistas con una enseñanza más práctica y técnica (Graña, 1927; Beneyto, 1958; Benito, 1967) y, más tarde, en la etapa postcientífica, en palabras de Fernández del Moral (1991), cuando el Periodismo llega a la Universidad y se reaviva la discusión de la enseñanza del Periodismo hasta la actualidad, con investigaciones en defensa del carácter científico y superior de esta rama del conocimiento (Aguinaga, 1980; Aguirre, 1988; Humanes, 1997; Galdón 1999; Videla, 2002; Real 2004; Sánchez-García, 2014). Entre estas investigaciones destaca, para el presente objeto de estudio, el enfoque originado por Enrique de Aguinaga (1980 y 1984) al relacionar la formación superior de los periodistas con la regulación profesional para determinar quién es y quién no es periodista según su cualificación y cerrar, así, el círculo inacabado que, siguiendo su teoría, provoca que la verdadera profesionalización del Periodismo siga pendiente. 
Las investigaciones más recientes sobre la formación de periodistas en el nuevo entorno mediático se dirigen, principalmente, a analizar la necesidad de integrar la enseñanza del Periodismo digital o multimedia en los planes de estudio con una visión integradora más allá del adiestramiento técnico (Salaverría, 2011; Díaz Noci, 2007; Meso, 2003; Tejedor, 2007). A ellas se unen los estudios sobre la adaptación de los programas formativos a los nuevos perfiles y roles profesionales en pleno proceso de definición (Montiel y Villalobos, 2005; López, 2009, 2012; Masip y Micó 2009; Sierra y Cabezuelo, 2010; Bello, 2013). Del mismo modo, la tercera perspectiva de análisis que estructura este artículo sobre la regulación profesional cuenta con un relato pormenorizado de los intentos de desarrollar una normativa en España, principalmente a través de un estatuto (Aznar, 2005; Varela, 2006; Real, 2009; Jiménez, 2011). Una cuestión que vuelve a revisarse en el nuevo entorno mediático que difumina la frontera entre la información profesional y la que no lo es.

\section{Objetivos y metodología}

La presente investigación surge con el objetivo de recoger la opinión de colectivos profesionales de periodistas en España en torno a cuestiones reavivadas en el debate académico actual sobre las necesidades formativas de los periodistas, la adaptación a los nuevos perfiles cambiantes y la conveniencia o no de regular la profesión mediante el título universitario. Y, en un segundo nivel, se plantea el objetivo de establecer un paralelismo de las posibles coincidencias y discrepancias al respecto entre el discurso científico y el profesional ante el actual panorama mediático en evolución.

El estudio parte con la hipótesis de que el ámbito académico y el profesional coinciden mayoritariamente en la defensa de la enseñanza superior del Periodismo y que reconocen la necesidad de adaptarla a los nuevos perfiles profesionales, así como establecer mecanismos de regulación profesional en concordancia con la cualificación requerida al periodista titulado.

La investigación recurre a una metodología mixta de tipo cualitativo mediante una revisión bibliográfica, que contribuye a una actualización del campo de conocimiento y a enmarcar las cuestiones centrales a plantear, y la técnica de la entrevista en profundidad con formulario de preguntas abiertas, dirigida a los portavoces de cinco colectivos de periodistas, que representan los intereses de más de 60.400 profesionales asociados. Esta técnica se considera adecuada porque solicita a cada portavoz profesional que responda con sus propias palabras facilitando así la libertad en la contestación y la posibilidad de respuestas de mayor profundidad, a la vez que permite indagar sobre el cómo y el porqué del objeto de estudio (Wimmer y Dominick, 1996). A partir de los resultados obtenidos se realiza un análisis del discurso académico y del profesional al objeto de establecer coincidencias y diferencias que permitan actualizar y concretar el debate.

La elección de la muestra acotada a cinco asociaciones y colectivos profesionales sigue tres criterios de representatividad:

- Número de asociados y la antigüedad del colectivo en cuestión.

- Su papel activo en el escenario actual, en el campo de la investigación (ámbito académico) o de la realidad periodística cambiante (ámbito profesional).

- La implicación en el debate de la regulación periodística en diferentes etapas. 
Mediante estos criterios se obtiene una representación de colectivos de diferente índole: los tres colectivos más numerosos y activos, que son protagonistas directos del debate sobre la legislación de un estatuto profesional, como es el caso de la Federación de Asociaciones de la Prensa (FAPE), la Federación de Sindicatos de Periodistas (FeSP) y la Asociación de la Prensa de Madrid (APM); la Sociedad Española de Periodística (SEP) como entidad impulsora de la investigación científica en Periodismo; y, por último, el Colegio de Periodistas de Cataluña, pionero en la defensa colegiada de los periodistas. Con esta elección puede considerarse representados tres tipos diferentes de agrupaciones que asisten a los periodistas: asociaciones, sindicatos, colegios profesionales e investigadores ${ }^{1}$.

La selección de la muestra, acotada por razones de operatividad, no es representativa de toda la profesión periodística española, sin que por ello invalide los resultados puesto que la finalidad primordial de este trabajo no es de carácter cuantitativo sino cualitativo. Es decir, no importa tanto el número como los argumentos que emplean los colectivos más representativos de la profesión e implicados más directamente en el objeto de estudio y que, además, responden como un actor social de gran relevancia, cuyas decisiones afectan a un considerable número de profesionales. En este análisis cualitativo interesa la argumentación de los portavoces profesionales para compararla con el discurso académico.

${ }^{1}$ La Federación de Sindicatos de Periodistas (FeSP) se pone en marcha en 2001 y cuenta con 2.700 sindicatos afiliados y 300 delegados sindicales que representan a más de 14.500 trabajadores. Responde a la entrevista su secretario general, Dardo Gómez, quien ocupa el cargo desde mayo de 2009.

La Federación de Asociaciones de Periodistas de España (FAPE) se crea en 1922. Cuenta con 48 asociaciones federadas y 13 vinculadas con representación de más de 20.000 asociados de toda España. Su presidenta, Elsa González, ejerce el cargo desde mayo de 2010 y es quien participa en la entrevista.

La Asociación de la Prensa de Madrid (APM) es la organización de periodistas más antigua de España, creada en 1895, y la más numerosa de ámbito regional al contar con más de 7.600 socios. Contesta a las preguntas de la encuesta su presidenta, nombrada en diciembre de 2011, Carmen del Riego.

La Federación de Sindicatos de Periodistas (FeSP) se pone en marcha en 2001 y cuenta con 2.700 sindicatos afiliados y 300 delegados sindicales que representan a más de 14.500 trabajadores. Responde al formulario su secretario general, Dardo Gómez, quien ocupa el cargo desde mayo de 2009.

El Colegio de Periodistas de Cataluña se crea en 1985 como una de las primeras iniciativas de colegiación de periodistas en España. Aglutina a distintos colectivos de profesionales catalanes con más de 3.700 socios. Participa en la entrevista Josep M. Martí i Martí, como decano entre mazo de 2010 y 2014, año en que ha sido sustituido por Neus Bonet.

La Sociedad Española de Periodística (SEP) se funda en 1989 y cuenta con 150 socios con la peculiaridad de que todos ellos son profesores e investigadores universitarios, procedentes de la mayoría de la Universidades españolas que ofrecen estudios de Comunicación. Responde a la entrevista Concha Edo quien es su presidenta desde mayo de 2010 hasta mediados de 2014, fecha en la que ha sido sustituida por Fernando López Pan. 
Para la realización de la entrevista, se envía un formulario mediante correo electrónico a los colectivos para que respondan los representantes que consideren ${ }^{2}$ con preguntas relacionadas con las tres perspectivas objeto de estudio: la importancia de la formación, el cambio de funciones y perfiles, y la regulación profesional mediante un estatuto.

En cuanto a la lectura de resultados se tienen en cuenta las posibles limitaciones que conlleva la técnica de entrevista con preguntas abiertas puesto que requiere de una interpretación en busca de categorías concluyentes que podrían introducir elementos de subjetividad. Para contrarrestarlo y facilitar la exposición de resultados con un enfoque integrador se ha optado por exponerlos en los tres apartados temáticos objeto de estudio, y con la inclusión de frases textuales de los portavoces participantes, combinadas con un resumen de sus argumentos. En cada uno de ellos se ha optado por presentar primero el discurso académico, a modo de contexto teórico previo que facilita el análisis posterior de las respuestas profesionales, siguiendo la teoría de que el contexto ayuda a "comprender en forma apropiada el suceso, la acción o el discurso" (Van Dijk, 2000: 32). Una estructura que, además, facilita la comparativa entre el discurso profesional y el académico, con el fin último de presentar unas conclusiones de carácter analítico-critico.

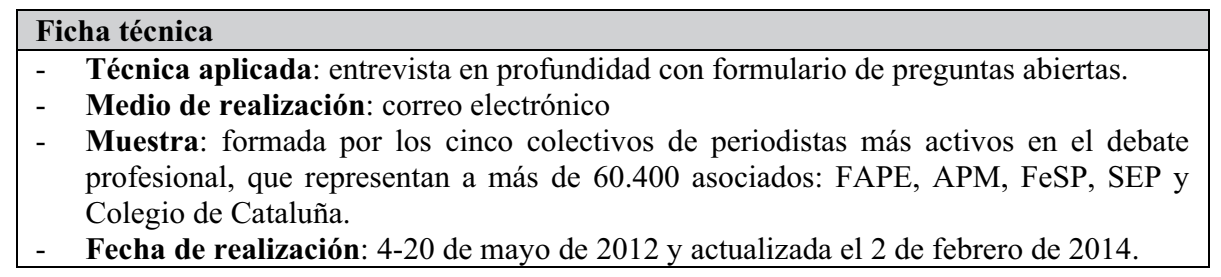

\section{Resultados}

\subsection{La revisión de las necesidades formativas y sus enfoques}

El debate teórico en torno a la formación de los periodistas sigue abierto (López, 2009; Pinto y Sousa 2003) en el ámbito académico. Como se ha explicado en la introducción, en España, al igual que en otros países del entorno europeo, la discusión acerca de la enseñanza periodística ha pasado por diferentes etapas y argumentos, desde el inicio de los primeros cursos con el seminario de Araujo (1887) y la Escuela de El Debate (1926), seguido del siguiente período de control formativo e informativo de la Dictadura Franquista a través de la Escuela Oficial de Periodistas (EOP, 1941-75) -que convivió con iniciativas privadas ligada a la Iglesia (Instituto de Navarra, 1958 y Escuela de la Iglesia, 1960)- hasta el inicio de la etapa universitaria (1971). Con un carácter de enseñanza instrumental, en la etapa "precientífica" (Fernández, 1991) el

2 Las entrevistas se realizan en varias fases. En un primer momento, fue enviado el formulario entre el 4 y el 20 de mayo de 2012 a través de correo electrónico a los colectivos que conforman la muestra, como parte de la Tesis Doctoral 'Un siglo de enseñanza periodística en España: de la primera Escuela a la adaptación de los estudios al Espacio Europeo de Educación Superior". Posteriormente es actualizada el 2 de febrero de 2014 con una ampliación de las cuestiones planteadas. 
Periodismo seguía considerado como un oficio (Aguinaga 1980) que no requería cualificación y el argumento a debatir era la conveniencia de la formación autodidacta en las redacciones o sistematizada en una escuela.

La llegada de estos estudios a la Universidad avivó, incluso, el debate en el ámbito académico y el profesional. De un lado, quienes no consideran el ejercicio periodístico como materia científica propia de una enseñanza superior y del otro, una parte de los propios periodistas que siguen apostando por la formación instrumental aplicada y autodidacta (Humanes 1997, Real 2004) que no aporta la enseñanza superior. Lejos de extinguirse, el debate se mantiene en esta etapa "postcientífica" (Fernández, 1991) dentro y fuera de la Universidad en dos planos diferenciados: por un lado, surgen voces críticas acerca de la idoneidad de una enseñanza universitaria y, en otro plano, se sigue debatiendo sobre si los planes de estudio de Periodismo requieren una formación más teórica o práctica, más especializada o multidisciplinar con las Ciencias sociales y las Humanidades de fondo (López, 2010). La discusión se prolonga en el siglo XXI, coincidiendo con el proceso de adaptación al Espacio Europeo de Educación Superior (EEES) y reactivada por la realidad comunicativa y tecnológica cambiante que difumina los límites del Periodismo y sus actores, y da lugar a una amalgama de estructuras, perfiles y soportes informativos a los que miran ahora profesionales e investigadores ante la necesidad de adaptación a la nueva realidad mediática. En este punto, y siguiendo la línea de Pinto y Sousa (2003), el nuevo argumento del debate formativo pasa por superar la tradicional dicotomía práctica/teoría para concentrar los esfuerzos en investigar los cambios de los medios y su nuevo rol en la sociedad, a fin de dar soluciones integrales y profundas para mejorar la calidad formativa y el ejercicio profesional de los periodistas.

Esta evolución recogida en el discurso teórico y académico sobre la formación de los periodistas en España ha generado un viejo e inacabado debate que puede diferenciarse en tres etapas en las que se aprecian algunos cambios en las temáticas de discusión (Tabla 1).

Tabla 1. Evolución del debate formativo de la enseñanza del Periodismo. Fuente: elaboración propia

\begin{tabular}{|l|l|}
\hline $\begin{array}{l}\text { Primera mitad del siglo XX } \\
\text { (Enseñanza en las escuelas) }\end{array}$ & $\begin{array}{l}\text { Debate sobre la formación técnica o } \\
\text { teórica del Periodismo considerado como } \\
\text { un oficio. }\end{array}$ \\
\hline $\begin{array}{l}\text { Segunda mitad del siglo XXI } \\
\text { (Enseñanza universitaria) }\end{array}$ & $\begin{array}{l}\text { Debate sobre el equilibrio entre la } \\
\text { formación específica y multidisciplinar en } \\
\text { la enseñanza universitaria del Periodismo } \\
\text { considerado como profesión. }\end{array}$ \\
\hline $\begin{array}{l}\text { Principios del siglo XXI } \\
\text { (Enseñanza en el EEES y y y } \\
\text { entorno multimedia) }\end{array}$ & $\begin{array}{l}\text { Debate sobre la adaptación de los planes } \\
\text { formativos al entorno europeo que } \\
\text { coincide con los cambios multimedia y la } \\
\text { aparición de nuevos perfiles profesionales } \\
\text { en el mercado laboral. }\end{array}$ \\
\hline
\end{tabular}

Frente al discurso académico en torno a la formación de los periodistas, se recoge ahora la opinión de los colectivos profesionales participantes en la entrevista realizada en el marco de la presente investigación. En relación a esta cuestión se les plantea la siguiente pregunta abierta: 
- ¿Considera importante la formación de los periodistas? ¿Piensa que para desarrollar la profesión periodística se hace necesario un título de Licenciado/Graduado/ o Máster en Periodismo? En el caso de que considere relevante la formación de los periodistas, conteste si la exigencia en su formación debe incrementarse en estos momentos.

A esta pregunta, que incluye varios matices, todos los colectivos participantes responden afirmativamente, en el sentido de que consideran que la formación de los periodistas es muy importante e incluso la mayoría resalta la necesidad de que sea más exigente, con contenido humanístico y práctico. Pero en sus respuestas surge una discrepancia fundamental, que muestra la relación que ellos mismos establecen entre el debate formativo y el de la regulación profesional que se aborda más adelante, en cuanto a la necesidad del título universitario de periodista. Y a este respecto, en un primer bloque puede decirse que las respuestas resultan más coincidentes entre la FAPE, la APM y la SEP, cuyos portavoces sí destacan la importancia de la titulación específica, como se detalla a continuación.

La presidenta de la Federación de Asociaciones de Periodistas (FAPE), Elsa González, califica de "fundamental" la formación de los periodistas e incluso recalca que no es una profesión "apta para aficionados" porque es una profesión "vital para la democracia" que está amparada por el Artículo 20 de la Constitución. Defiende la formación universitaria, como mínimo de segundo ciclo, con una "base cultural reforzada y una formación sólida específica". Critica que "la salida prematura de los medios de comunicación de los periodistas senior, experimentados, está dificultando la formación y las transmisión de los principios del periodismo a las nuevas generaciones".

Desde la Asociación de la Prensa de Madrid (APM), su presidenta Carmen del Riego defiende que la formación de los periodistas es "básica para el ejercicio de la profesión" y recalca que es el título universitario el que debe garantizar esos conocimientos "como único vehículo" para que los periodistas sean garantes del derecho a la información. Y en esta preparación, en su discurso apuesta, de forma concreta y explícita, por la conveniencia de una enseñanza general humanística apoyada en "economía, historia, literatura, filosofía, derecho" para entender la actualidad y, con asignaturas específicas de la profesión, en especial, señala las relacionadas con la ética y la deontología.

En la misma línea se expresa, en representación de la Sociedad Española de Periodística (SEP), Concha Edo quien considera "imprescindible" la formación de los periodistas, con un título "necesario" y señala como "deseable la colegiación, como en otros colectivos". En cuanto al enfoque actual de los estudios en las universidades españolas, cree que en muchos casos resulta "obsoleto y frecuentemente alejado de la realidad de la práctica profesional". Destaca especialmente la formación adaptada a los nuevos cambios tecnológicos del sector y para ello aboga por una "formación profesional y cultural más completa y exigente" y apunta, en concreto, al refuerzo de la enseñanza en el conocimiento de la dinámica de los cibermedios, las redes sociales y la participación ciudadana y el dominio de varios idiomas.

El secretario general de la Federación de Sindicatos de Periodistas (FeSP), Dardo Gómez, considera igualmente importante la formación de periodistas como "para un 
capitán de barco", pero rechaza abiertamente que "la titulación -por sí sola-, deba ser habilitante para el ejercicio" y critica que la formación ofrecida a los periodistas no resulta "idónea y suficiente". Señala que existen en la actualidad nuevas exigencias que requieren la necesidad de combinar "preparación técnica y humanística", conocimiento de la profesión y responsabilidad social, además de formación sobre la gestión de la empresa periodística y producción de los medios.

Desde el Colegio de Periodistas de Cataluña, José María Martí no muestra ninguna duda en torno a la relevancia de la formación de los periodistas para "ejercer correctamente su oficio" pero no considera que la formación universitaria sea la principal vía para este aprendizaje. Añade que deben replantearse los estudios formativos o el número de centros y que ante "la eclosión de las nuevas tecnologías" se exige "una formación constante del periodista".

\subsection{Los nuevos perfiles periodísticos como salidas laborales}

Las investigaciones científicas en torno a la relación entre la formación de periodistas y el nuevo entorno mediático pueden resumirse en dos temáticas que, a su vez, incluyen numerosas perspectivas: la incorporación de las nuevas tecnologías de forma integral en los planes de estudio y la adaptación de las enseñanzas a los nuevos perfiles periodísticos. En la actual transformación mediática y comunicativa, "los periodistas han tenido que asumir tareas que tradicionalmente eran propias de otros profesionales, lo que les ha forzado a desarrollar un perfil más complejo y exigente" (Masip y Micó, 2009: 93) que requiere una revisión de su formación. El debate académico en este sentido se centra, principalmente, en saber cómo han cambiado las funciones y los roles de los periodistas y cómo debe combinarse la realidad del mercado laboral con la enseñanza superior.

La integración del Periodismo digital -en sus diferentes acepciones y perspectivas de Periodismo tecnológico, multimedia o Ciberperiodismo-, resulta 'tímida' en los programas universitarios en España (Salaverría, 2011). La adaptación formativa a los nuevos medios se encuentra inmersa en un doble debate que genera una nueva dicotomía en el discurso académico: la de formar periodistas para medios digitales con refuerzo de la capacitación instrumental o preparar periodistas polivalentes y con capacidad multimedia integrando la tecnología en la labor periodística y no al revés (Díaz, 2007; Tejedor, 2006). Las investigaciones a este respecto se inician en España a principios del siglo XXI y el debate igualmente sigue abierto. El ámbito académico destaca que el nuevo ecosistema comunicativo "ha definido perfiles que exigen una preparación distinta a la que hasta ahora han recibido los periodistas" (López, 2001: 14) puesto que se trata de perfiles polivalentes, flexibles y versátiles que aplican esos mismos adjetivos a las competencias y cualidades con que debe contar el periodista actual.

Con este discurso científico de fondo, se recoge la opinión de colectivos profesionales en torno al cambio de funciones y perfiles de los periodistas en activo. Los portavoces de los cinco colectivos entrevistados responden a las siguientes preguntas:

- En la realidad periodística actual, ¿detecta nuevos perfiles profesionales? ¿Constata que puedan haber variado las funciones que venían cumpliendo los 
periodistas? Si es así, mencione cuáles son las funciones que pueden haber desaparecido y cuáles se han incorporado en los últimos años.

Como se expone a continuación, el análisis del discurso en el ámbito profesional sobre esta cuestión muestra cómo los representantes de los colectivos periodísticos detectan variaciones relevantes de perfiles que relacionan con el cambio tecnológico y que consideran nuevas oportunidades laborales. La mayoría destaca que las funciones tradicionales del periodista no varían.

La portavoz de la FAPE, Elsa González, señala que, en la realidad tecnológica que afecta al sector, surgen "nuevos nichos de empleo" en el marco de una nueva Sociedad de la Información. Describe la actual realidad profesional con los cambios informativos constantes, las nuevas fuentes de información que representan las redes sociales, el movimiento permanente de los medios digitales y la avidez de información del público fuera de los medios tradicionales. Pero ante este cambio de panorama, González considera que la función del periodista y de los medios de comunicación sigue siendo la misma: "ser garantes del Derecho del ciudadano a recibir una información libre y veraz; ser vigilantes del poder de todo tipo; destapar corrupciones o abusos; dar voz a quien no tiene acceso a ser oído, aunque este es uno de los puntos que, en gran medida, ha solucionado la tecnología". Recalca que, en este nuevo entorno mediático, los periodistas son ahora "más necesarios que nunca".

Desde la APM, su presidenta, Carmen del Riego, considera que "la esencia del trabajo del periodista sigue siendo la misma: informar, obteniendo información, contrastándola, digiriéndola y transmitiéndosela a los ciudadanos para que puedan entender la realidad en la que viven". En su opinión, en lo que sí aporta cambios la realidad periodística actual es en incrementar el campo de trabajo del periodista, especialmente en un amplio ámbito de la Comunicación con nuevas tareas relacionadas con las redes sociales. Y coincide con la presidenta de la FAPE al referirse a "nichos laborales" nuevos y pone como ejemplo de ellos el asesorar sobre qué tipo de informaciones deben ubicar en las redes las empresas, instituciones, etc., para atraer a quienes las visitan.

Concha Edo (SEP) constata igualmente que ante los cambios tecnológicos y laborales "los periodistas deben mantener inalterables sus funciones profesionales centradas en ofrecer información veraz, interesante, documentada, rigurosa y estructurada profesionalmente, sea cual sea el soporte utilizado: las mejoras tecnológicas no deberían llevar a la superficialidad". Reconoce los cambios en los nuevos perfiles para "saber interactuar con la audiencia a través de las redes sociales y de la web de su medio", pero sin perder la máxima exigencia de calidad. En esta nueva era digital, Edo denuncia un refuerzo del intrusismo al amparo de las nuevas tecnologías que el profesional debe contrarrestar con "especialización actualizada".

El secretario general de FeSP, Dardo Gómez, reitera que "la función de informar no ha cambiado; los principios éticos que deben regirla, tampoco; y su función social es tan innegable como siempre y más necesaria que nunca". Constata que sí se han producido otras variaciones en las plataformas de emisión del mensaje, las herramientas y las rutinas de trabajo. Unos cambios que, en su opinión, permiten a los periodistas 
"ser más eficaces e informar mejor", al tiempo que critica que la calidad periodística no es la preocupación principal de las empresas, ante lo que esgrime la necesidad de una regulación profesional y laboral.

Josep M. Martí, desde el Colegio de Periodistas de Cataluña, defiende que las nuevas tecnologías "también están introduciendo nuevos perfiles, como podrían ser los community manager, y todos aquellos profesionales que pueden vincularse con la gestión de contenidos". Martí coincide en destacar que existen tareas que se están adaptando a la realidad "pero sin alterar el concepto ni la función social que desempeña el periodismo".

\subsection{Discrepancias ante la regulación profesional y el estatuto fallido}

El ejercicio profesional del Periodismo puede desempeñarse en España sin necesidad de un título universitario específico, como ocurre en la mayor parte de los países europeos del entorno. Aún así, las cifras de titulados universitarios en Periodismo -más de 70.000 en España (APM, 2014)- y la oferta creciente de más de 40 Universidades con estudios de Comunicación (ANECA, 2005) evidencian que la formación universitaria del Periodismo se impone en la realidad actual.

En los argumentos que centran este debate teórico, existen dos vertientes: las de quienes consideran la regulación contraria al derecho constitucional de la libertad de información y la de quienes consideran cualquier intento de regulación como una rémora del control franquista ejercido a través de Registro Profesional de Periodistas ligado a la escuela Oficial de Periodistas y del primer y único estatuto profesional del periodista aprobado el 13 de abril de 1967 y derogado en la Transición democrática (Humanes, 1997). Es decir, la dicotomía del debate surge en considerar la regulación profesional como una forma de control informativo o como una garantía de los derechos ciudadanos. Y el debate se enraíza aún más al adentrarse en la redacción de un hipotético estatuto donde se establezca o no la titulación universitaria específica como única vía de acceso al ejercicio del Periodismo.

En el discurso científico se considera que en esta cuestión subyacen dos maneras de entender el Periodismo que, en cierto sentido, siguen vigentes: la visión del Periodismo como oficio que se adquiere con la experiencia o la de una profesión sujeta a los conocimientos de un corpus científico. "El nuevo profesional se caracteriza por el dominio de un saber científico-técnico, cuya acreditación le será exigida para poder ejercer la profesión" (Real, 2004: 46). Desde esta perspectiva se considera que la regulación sería beneficiosa "por el título académico y la identidad y solidaridad del cuerpo profesional que abarca a las personas que poseen el mismo título o licencia y se materializaría en un código de ética y unos estatutos profesionales" (López, Papí y Martín, 2010:134). Aún así, no se conocen iniciativas universitarias conjuntas en España encaminadas a reclamar el reconocimiento legal del título de sus estudiantes de Periodismo.

Los discursos contrapuestos se ponen más claramente de manifiesto en el ámbito profesional, especialmente a partir de la aprobación provisional de la Proposición de Ley de Estatuto del Periodista en 2004, impulsada por el Foro de Organizaciones de Periodistas (FOP), debatida en el Parlamento español. Su admisión a trámite en el Congreso de los Diputados, el 23 de noviembre de 2004, reflejó la polémica entre diversos sectores del Periodismo y provocó que la FAPE se desvinculara del FOP y de 
la iniciativa, que finalmente no fue aprobada. Al objeto de constatar y actualizar la revisión de estas posturas diez años después del debate parlamentario, esta investigación recaba la opinión de los representantes de los colectivos profesionales al respecto, la mayoría de ellos implicados directamente en dicha iniciativa parlamentaria. El formulario de esta investigación recoge dos preguntas abiertas:

- ¿Cree necesaria la elaboración de un Estatuto Profesional del Periodista? ¿Por qué?

- ¿Qué cree que ha provocado que dicho Estatuto de la Profesión Periodística siga paralizado tras su debate en el Congreso en 2004 ?

En sus respuestas se aprecian las discrepancias intactas entre los colectivos profesionales después de una década en lo que puede considerarse un debate estancado en dos cuestiones, principalmente: la autorregulación frente a la defensa de un estatuto y la exigencia o no de un título universitario como vía única de acceso a la profesión.

La presidenta de la FAPE, Elsa González, recuerda que su organización rechazó el proyecto de estatuto porque "podría ser intervencionista y lesivo para los intereses de la profesión". Este colectivo apuesta por otras formas de autorregulación para que sean los periodistas quienes "asumen un código deontológico con principios éticos para el ejercicio profesional". La FAPE cuenta con la Comisión de Quejas y Deontología, "ahora amparada por una Fundación para conferirle mayor independencia, está desarrollando un órgano de autocontrol ajeno a los vaivenes políticos y del estilo de la Comisión de Quejas británica". En cuanto a las causas de que siga paralizado el Proyecto de Ley del Estatuto del periodista profesional de 2004 lo achaca a la ausencia de las asociaciones profesionales agrupadas en la FAPE, como colectivo profesional mayoritario, que sí defienden la titulación universitaria de Periodismo "como única vía de acceso a la profesión" al tiempo que rechazan "las sanciones expuestas a intereses políticos, que limitan la libertad de información" y que figuraban en el proyecto estatutario.

En coherencia con la postura de la FAPE, su asociación provincial más numerosa, la APM, apuesta igualmente por la vía de la autorregulación periodística como la "fórmula ideal" en palabras de su presidenta, Carmen del Riego, al considerar que un estatuto "limitaría más el ejercicio de la profesión que el que pudiera resultar de la autorregulación". Aun así, reconoce la necesidad de que, a través de autorregulación y otros estatutos, "se establezca más claramente quién es periodista o los requisitos que debe cumplir", junto a normas éticas y deontológicas. La paralización del trámite estatutario la achaca a que en su origen está concebido por el Sindicato de Periodistas y asumido en el Congreso por IU sin el apoyo de más partidos ni de las asociaciones de la prensa, "a los que se ignoraba". Del Riego introduce un nuevo argumento al señalar que el texto fallido contenía algunos puntos no admisibles, en su opinión, como "la creación de un Consejo estatal de la Información que era el único autorizado para otorgar el carnet de periodista, donde daba voz a sindicatos y asociaciones de consumidores y, sin embargo, no a las asociaciones de la prensa".

Desde la Sociedad Española de Periodística (SEP), Concha Edo responde con un 'no' tajante a cualquier tipo de regulación porque "cuando se plantean condiciones 
especiales para la profesión periodística siempre se concretan en recortes de la libertad y en controlar su trabajo" y considera suficiente el marco de las leyes generales de los trabajadores para aplicarlas al sector periodístico. Argumenta que la paralización del proyecto de ley es la "evidencia de intereses ajenos al Periodismo en su redacción" y añade que los periodistas "no quieren ser dirigidos desde instancias oficiales ni quieren ver mermada la necesaria libertad para informar que defiende el marco legal vigente".

En el lado opuesto a estas consideraciones figuran las agrupaciones sindicales y el Colegio de Cataluña, ambos claramente a favor de la regulación mediante un estatuto pero sin exigencia de un título universitario. El secretario general de FeSP, Dardo Gómez, defiende el Proyecto de Ley de Estatuto Profesional que impulsó su sindicato, como integrante del FOP, en 2004. Gómez considera que la normativa es necesaria para proteger y garantizar el derecho a la información "mediante la regulación de los agentes y medios que deben satisfacer como función social esos derechos". En su opinión, es la ausencia de regulación lo que facilita en España que la información sea "patrimonio de los grupos multimedia" con la consiguiente "degradación informativa que hoy vivimos, que ya atenta gravemente contra la supervivencia de la democracia". Gómez argumenta que el estancamiento del estatuto se debe a "la falta de coraje cívico de los dos grandes partidos españoles y algunos subalternos que no han sabido resistir la presión de los grandes medios". A estas razones añade la confusión que, según su criterio, han tenido algunas asociaciones profesionales "que recién ahora están percibiendo a los informadores como trabajadores de la información y la influencia negativa de las patronales sobre esas organizaciones". Desde su organización se ha impulsado en la actualidad la alternativa de la 'Ley de Garantías del Derecho a la Información de la Ciudadanía'.

En representación del Colegio de Periodistas de Cataluña, Josep M. Martí i Martí, muestra claramente la postura de su organización a favor de la creación de un estatuto profesional por la conveniencia de "regular la profesión de periodista y garantizar que se cumple bajo las premisas de un código deontológico que ampare la función de servicio público del periodismo". Además, recuerda que el propio Colegio catalán, el primero en constituirse en España hace más de 25 años, dispone de sus propios estatutos profesionales "con la voluntad de garantizar la buena praxis periodística". Martí justifica la paralización del trámite de estatuto por un "elemento clave", el de la falta de unión profesional "escenificada" en la salida de la FAPE de la iniciativa legislativa del FOP, a lo que suma otros dos motivos como "las distintas carencias jurídicas que podían poner en entredicho la posible aprobación de la Ley" y que "el sector empresarial no haya mostrado jamás ninguna satisfacción por esta iniciativa legislativa".

\section{Discusión y conclusiones}

La investigación desarrollada en este artículo permite dar por conseguido el objetivo planteado inicialmente de recabar la postura de los colectivos profesionales en torno a la formación de periodistas, su adaptación al cambio de perfiles laborales y la regulación profesional vinculada al título, con el fin último de establecer paralelismos entre los discursos del ámbito académico y profesional al respecto. 
Como se expone a continuación, el estudio permite confirmar en parte la hipótesis de partida en el sentido de que el ámbito académico y profesional reconocen la importancia de la enseñanza superior para el ejercicio del Periodismo y la necesidad de adaptarla a los nuevos perfiles profesionales cambiantes. Sin embargo, no puede confirmarse que exista un discurso unánime en cuanto a la regulación profesional vinculada al título universitario debido a las discrepancias manifestadas especialmente en el ámbito profesional en torno a los mecanismos de regulación, y la falta de prioridad en el ámbito académico.

A partir de esta constatación general, el desarrollo de la investigación ofrece matices expresados en conclusiones concretas obtenidas en cada una de las tres perspectivas analizadas. La investigación refleja cómo en los diferentes discursos del ámbito académico y del profesional sí existe una interrelación entre las tres temáticas que centran el objeto de estudio: la formación universitaria de los periodistas ligada a la adaptación de los nuevos perfiles mediáticos y el reconocimiento de su cualificación mediante la regulación profesional. A este respecto, el estudio confirma que el debate sobre las tres cuestiones planteadas sigue abierto en España.

El análisis del discurso académico sobre la formación de los periodistas refleja un avance de argumentos desde la antigua percepción del Periodismo como oficio a la visión profesional actual pero existe aún una discusión en torno a los equilibrios necesarios entre la formación práctica o teórica; especializada o multidisciplinar. $\mathrm{La}$ necesidad de una formación universitaria expresada en el discurso teórico coincide con la postura de los colectivos profesionales que también la defienden aunque se muestran críticos en cuanto a la calidad de la formación actual de los periodistas en la Universidad y reclaman una formación cultural, humanística sólida que se compagine con la técnica y práctica. En lo que discrepa el ámbito profesional internamente es en que la titulación específica universitaria sea utilizada como vía de acceso única a la profesión. Lo reclaman así expresamente la APM y SEP y lo rechazan FeSP y el Colegio de Cataluña que consideran otras vías posibles de formación y acceso profesional, especialmente basadas en la experiencia en medios de comunicación.

El discurso académico y profesional muestra igualmente coincidencias respecto a que la función social del Periodismo no varía en el nuevo entorno mediático aunque sí surgen nuevos perfiles profesionales que suponen nuevos "nichos" o "salidas laborales". Los colectivos profesionales muestran la confianza en las nuevas tecnologías como herramientas de trabajo e introducen en sus discursos dos cuestiones que no se les plantean directamente: el papel necesario del periodista en la nueva realidad mediática y el temor al intrusismo que pueden fomentar los nuevos medios y redes sociales. Estos cambios destacados por los profesionales coinciden con el incremento del interés investigador en torno a esta nueva realidad enfocado a cómo adaptar la enseñanza del Periodismo a los perfiles emergentes.

La cuestión de la regulación profesional constituye un asunto de división entre los diferentes colectivos de periodistas y parece no despertar el mismo interés reivindicativo en el ámbito académico. Las respuestas expresadas por los portavoces de las agrupaciones consultadas evidencian que la división en el ámbito profesional se mantiene a este respecto en la actualidad enfrentando dos posturas: la defensa de un sis- 
tema de regulación o autorregulación vinculado a la titulación universitaria de Periodismo, frente a la postura a favor de un estatuto profesional específico pero sin vinculación con la titulación como única vía de acceso a la profesión. El discurso en este caso puede considerarse estancado puesto que los colectivos profesionales reproducen, de forma prácticamente idéntica, las mismas posturas de hace diez años cuando se aprobó provisionalmente la 'Ley de Estatuto profesional del periodistas' debatido en el Congreso de los Diputados: la FAPE, la APM y la SEP defienden la regulación basada en la titulación específica, aunque no consideran imprescindible el estatuto; y, por otro lado, la agrupación sindical FeSP y el Colegio de Cataluña apoyan un estatuto profesional pero no consideran imprescindible la exigencia del título universitario específico para el ejercicio profesional.

En definitiva, la investigación refleja que los cambios profesionales encuentran su reflejo en las investigaciones académicas y que en ambos discursos se reconoce la necesidad de proceder a una adaptación permanente de las necesidades formativas de los periodistas a la realidad laboral cambiante. La cuestión estudiada no se agota en esta investigación si no que, muy al contrario, reafirma que se trata de un debate abierto y en evolución. En este proceso se hace patente la conveniencia de explorar nuevas vías de encuentro para redactar una 'hoja de ruta' que permita buscar más puntos de convergencia entre el ámbito profesional y el científico-académico en pos del mejor Periodismo posible en una realidad comunicativa cada vez más sofisticada y compleja.

\section{Referencias bibliográficas}

AGUINAGA, Enrique (1980): Periodismo Profesión. Madrid, Fragua.

AGUINAGA, Enrique (1984): "Epistemología del ejercicio periodístico. Los estudios de periodismo y su proyección profesional". Tesis inédita. Madrid, Universidad Complutense.

AGUIRRE, Marisa (1988): El deber de formación en el informador. Pamplona, Eunsa.

ANECA, Agencia Nacional de Evaluación de la Calidad y Acreditación (2005): "Libro Blanco. Títulos de Grado en Comunicación": [Consulta: 3 de febrero de 2010] http://www.aneca.es/var/media/150336/libroblanco_comunicacion_def.pdf

ASOCIACIÓN DE LA PRENSA DE MADRID, APM (2014): Informe Anual de la Profesión Periodística. Madrid, Asociación de la Prensa de Madrid.

AREAL, Manuel (2010): "Una profesión titulada "Periodismo". Revista Latina de Comunicación Social, 65. Tenerife, Universidad de La Laguna, pp. 1- 13. DOI: 10.4185/RLCS-65-2010-879-001-013.

AZNAR, Hugo (2005): Comunicación responsable. La autorregulación de los medios. Barcelona, Ariel.

BENEYTO, Juan (1958): “España”. En UNESCO: La formación de periodistas. Estudio mundial sobre la preparación del personal de la información. París, Unesco, pp. 199-202. [Consulta: 3 de abril de 2013] http://unesdoc.unesco.org/images/0013/001353/135346so.pdf 
BENITO, Ángel (1967): "Evolución de los estudios de Periodismo en el mundo", en "Ciencia y enseñanza del Periodismo", Cuadernos de Trabajo, núm. 11, pp.13-36. Pamplona, Universidad de Navarra.

DÍAZ-NOCI, Javier (2007): "Perspectivas de la investigación y docencia universitarias de la comunicación periodística", en GÓMEZ, Beatriz y HERNÁNDEZ, Sira (Eds.): Estudios de Periodistica XIII. La Periodística como disciplina universitaria: balance y perspectivas. Pamplona, Diario de Navarra y Sociedad Española de Periodística, pp. 31-39.

FERNÁNDEZ, Javier (1991): "Información Periodística Especializada", en BENITO, Ángel (Coord.): Diccionario de Ciencias y Técnicas de la Comunicación. Madrid, Ediciones Paulinas, pp. 764-784.

GALDÓN, Gabriel (1999): La enseñanza del Periodismo. Una propuesta de futuro. Barcelona, CIMS.

GRAÑA, Manuel (1927): "Escuelas de Periodismo", en Enseñanza profesional, pp. 240-252. Conferencia pronunciada en la Sociedad de Estudios Vasca. http://www.euskomedia.org/PDFAnlt/congresos/04/04240252.pdf [Consulta: 2 de febrero de 2012]

HUMANES, María Luisa (1997): La formación de los periodistas en España. Tesis doctoral inédita. Madrid, Universidad Complutense de Madrid.

JIMÉNEZ, Eva (2011): “Autorregulación versus regulación. El discurso periodístico sobre la Proposición de Ley de Estatuto del periodista profesional (2004-2008)". Estudios sobre el mensaje periodístico, vol. 17, núm. 1, pp.141-166. Madrid, Servicio de Publicaciones de la Universidad Complutense.

LÓPEZ, Sonia.; PAPÍ, Natalia; y MARTÍN, Marta (2010): "Los estudios de comunicación y el ejercicio profesional en España ante la convergencia europea", en SIERRA, Javier (Ed./Coord.): Los estudios de Ciencias de la Comunicación en el EEES. Madrid, Fragua, pp. 133-139.

LÓPEZ, Xosé (2001): "Nuevos perfiles de los periodistas en la sociedad de la información". Ámbitos, $\mathrm{N}^{\mathrm{o}}$ 7-8, pp. 7-18. http://congreso.us.es/grehcco/ambitos0708/xose.pdf [Consulta: 8 de noviembre de 2014]

LÓPEZ, Xosé (2009): “Tendencias en la formación de los periodistas en los ámbitos hispanos y lusófonos en el siglo XXI". Estudios sobre el Mensaje Periodístico, vol. 15, pp. 295-313. Madrid, Servicio de Publicaciones de la Universidad Complutense.

LÓPEZ, Xosé (2012): "La formación de los periodistas para los entornos digitales actuales". Revista de Comunicación, 11, pp. 178-195.

MASIP, Pere y MICÓ, Josep Lluís (2009): "El periodista polivalente en el marco de la convergencia empresarial". Quaderns del CAC, 31-32, pp. 91-99. Consejo del Audiovisual de Cataluña. 
MELLADO, Claudia; SIMÓN, Jeanne; BARRÍA, Sergio; y ENRÍQUEZ, Jorge (2007): "Investigación de perfiles profesionales en periodismo y comunicación para una actualización curricular permanente". Zer, 23, pp. 139-164.

MESO, Koldo (2003): "La formación del periodista digital". Chasqui, Revista Latinoamericana de Comunicación, núm. 84, pp. 4-11. Quito: Quipus-Ciespal,

MONTIEL, Maryalejandra y VILLALOBOS, Fernando (2005): "La enseñanza del periodismo en el siglo XXI: un desafío entre lo impreso y lo digital". Telos, vol. 7, núm. 3, pp. 397-411. Madrid, Fundación Telefónica.

PALOMO, Bella (2013): "Claves de la implantación y la expansión del perfil social del periodista". Comunicación y Medios, 28, pp. 113-129. Santiago de Chile, Universidad de Chile.

PINTO, Manuel y SOUSA, Helena (2003): "Journalism Education at universities and journalism schools in Portugal", en FRÖLICH, Romy \& HOLTZ-BACHA, Christina: Journalism education in Europe and North America. An international comparison. New Jersey, Hampton Press, pp. 169-186.

REAL, Elena (2004): Formación y ejercicio profesional del periodista en la España del siglo XXI dentro del marco de la Unión Europea. Tesis doctoral inédita. Madrid, Universidad Complutense.

REAL, Elena (2009): "La identidad del periodista en el futuro estatuto profesional, entre la confusión y la desprofesionalización". Estudios sobre el mensaje periodístico, vol. 15, pp. 95-118. Madrid, Servicio de Publicaciones de la Universidad Complutense.

SALAVERRÍA, Ramón (2011): "Online journalism meets the university: ideas for teaching and research". Brazilian Journalism Research, vol. 7, num. 11, pp.137152. Sociedad Brasileña de Investigación en periodismo.

SÁNCHEZ-GARCÍA, Pilar (2014): Un siglo de enseñanza periodística en España: de la primera escuela a la adaptación de los estudios al EEES. Tesis doctoral inédita. Valladolid, Universidad de Valladolid.

SIERRA, Javier y CABEZUELO, Francisco (Coords., 2010): Competencias y perfiles profesionales en los estudios de Ciencias de la Comunicación. Madrid, Fragua.

TEJEDOR, Santiago (2006): La enseñanza del ciberperiodismo en las licenciaturas de periodismo en España. Tesis doctoral inédita. Barcelona, Universidad Autónoma de Barcelona.

VAN DIJK, Teun (2000): El discurso como interacción social. Barcelona, Gedisa.

VARELA, JUAN (2006). "Lecciones de un estatuto moribundo" (Blog personal). http://periodistas $21 . b \log s$ pot.com/2006/09/1ecciones-de-un-estatutomoribundo.html [Consulta: 14 de abril de 2010]. 
VIDELA, José Juan (2002): La formación de los periodistas en España: perspectiva histórica y propuestas de futuro. Tesis doctoral inédita. Madrid, Universidad Complutense de Madrid.

WIMMER Roger D. y DOMINICK Joseph R. (1996): La investigación científica de los medios de comunicación: una introducción a sus métodos. Barcelona, Bosch.

Pilar Sánchez-García es doctora en Periodismo. Profesora Asociada en el Departamento de Historia Moderna, Contemporánea, de América, Periodismo y Comunicación Audiovisual y Publicidad de la Universidad de Valladolid. 